\title{
COMO E PORQUE SOU CRÍTICO
}

http://dx.doi.org/10.11606/issn.2237-1184.v0i30p237-242

Antonio Candido

$\mathrm{P}$ famílias coalhadas de médicos - pai, avô, tios-avós, tios, primos; destinado desde sempre por meu pai a estudar medicina, cresci conformado com isso, como se não houvesse outra solução possível e, portanto, nunca tive vocação para nada. Não queria ser médico, mas aceitei o que parecia ser a própria fatalidade, chegando a ser reprovado nos exames de ingresso à Faculdade de Medicina da USP em 1936, o que foi o primeiro passo para a libertação.

O meu impulso incoercível foi sempre ler, ler sem parar a partir dos meus seis ou sete anos, inclusive textos sobre obras e autores, chegando a folhear desde cedo com prazer a História da literatura brasileira de Sílvio Romero, o que talvez indique a predisposição misteriosa para a crítica... Quem sabe? Seja como for, nunca pensei, ao contrário de tantos adolescentes intelectualizados, em publicar o que quer que fosse, até que com quase 23 anos fui praticamente obrigado a isso, como contarei daqui a pouco.

Meu pai, médico muito culto, assinava ou comprava revistas literárias, que talvez tenham sido a base do meu trabalho crítico. Mas assim foi que em 1931 assinou o Boletim de Ariel, "Mensário crítico e bibliográfico" que se publicou no Rio de Janeiro daquele ano até 1939 e teve peso no movimento literário. É possível que ele tenha sido um estímulo básico a partir dos meus treze anos, pois eu tinha um prazer especial em ler artigos e notas sobre livros e autores, bem como notícias sobre a vida literária, e quem sabe isso foi a semente do que se pode chamar "espírito de resenha", isto é, a futura disposição de comentar por escrito os livros lidos.

Ao mesmo tempo eu era apaixonado por antologias escolares, brasileiras e estrangeiras, o que me levou a fazer em cadernos as minhas

I Universidade de São Paulo, São Paulo, São Paulo, Brasil. 
próprias, lendo muita coisa para escolher os textos que me pareciam interessantes. Por preguiça, nem sempre chegava a transcrevê-los depois de escolhidos, mas fazia um título caprichado e se possível colocava o retrato do autor, cortado de revistas e jornais, deixando em branco um certo número de páginas para cópia posterior. Esta nem sempre chegava a ser feita, mas o importante foi que no trabalho de escolha eu ia adquirindo o "espírito de seleção", a capacidade de discernir e avaliar, requisito básico do crítico e segundo elemento do aprendizado inconsciente.

A estes se juntou um terceiro traço formador, que se poderia denominar "espírito de contextualização", isto é, a referência da obra e do autor à sociedade e à época, desenvolvido em mim a partir do interesse precoce, profundo e duradouro pela história - dos povos, dos países, dos períodos, dos atores. Desde que aprendi a ler com minha mãe, eu o alimentei por meio dos compêndios, de certas seções do Tesouro da Juventude, a que tinha o título geral de História da terra, da humanidade na revista mensal Eu sei tudo, marcada por grande riqueza de ilustrações. A partir dos doze anos meu pai me encaminhou para a leitura da obra de Oliveira Martins, que ele tinha lido quando aluno do ginásio estadual de Campinas, o famoso Culto à Ciência, e me fascinou pela flama da visão e a escrita admirável. Mais tarde, esse "espírito de contextualização" amadureceria na universidade pelo estudo da sociologia, sobretudo na obra de Durkheim, e pelas leituras marxistas.

A partir de certa altura esta trinca (espírito de resenha, espírito de seleção e espírito de contextualização) foi se articulando devido a uma sugestão de minha mãe, mulher luminosa e grande leitora. Foi o seguinte. Eu estava começando o $4^{\circ}$ ano do Ginásio Municipal de Poços de Caldas e ela, me vendo resumir por escrito um texto de divulgação sobre os filósofos gregos, me aconselhou a adquirir o hábito de registrar em cadernos as minhas impressões de leitura, por mais sumárias e modestas que fossem. Aceitei o conselho e o segui com interrupções pela vida afora, enchendo cadernos incontáveis que inclusive serviram com o tempo de material para cursos e artigos.

Aconteceu então que no começo de 1941, já estudante na Faculdade de Filosofia da USP, de férias na casa de meus pais em Poços, recebi cartas de Alfredo Mesquita e Lourival Gomes Machado informando que tinham planejado fundar uma revista para servir de veículo às ideias do nosso grupo da Faculdade, que Alfredo, mais velho e escritor já conhecido, frequentava como ouvinte. E que eu seria o encarregado da seção de livros. Respondi alarmado que não tinha qualquer experiência disso e não poderia aceitar. Eles não me ouviram, fundou-se a revista Clima e eu me tornei o seu crítico literário... Passei então a publicar sem dificuldade artigos mensais, perguntando mais tarde a mim mesmo como isso foi possível, até que um dia veio a explicação: naquela altura eu já tinha me exercitado ao encher mais de dez cadernos com impressões de leitura, a 
partir da sugestão de minha mãe. Impressões que não tinham qualquer finalidade externa, mas devem ter sido uma espécie de tirocínio.

Em Clima definiram-se também Décio de Almeida Prado na crítica teatral, Paulo Emílio Salles Gomes na de cinema, Lourival Gomes Machado na de artes plásticas, Antonio Branco Lefèvre na de música, Roberto Pinto de Souza na de economia. Ser ter seção própria, atuaram de modo versátil os caçulas Gilda de Moraes Rocha e Ruy de Andrada Coelho. Certa vez perguntaram a este numa entrevista como tínhamos feito Clima. Ele respondeu: "Nós não fizemos Clima, foi Clima que nos fez". Nada mais exato para caracterizar o grupo que nos uniu e definiu, marcado por um traço comum que favorecia o pendor para a crítica e eu qualifiquei como "paixão pelo concreto". Esse grupo chegou a ter uma certa presença em São Paulo, inclusive como ponte entre a cultura universitária e a da cidade, o que começou logo. Por exemplo: menos de dois anos depois do lançamento de Clima, Lourival e eu éramos críticos titulares com seção própria, ele de artes plásticas, eu de literatura, de um grande jornal, a Folha da Manhã, hoje de São Paulo. Com isso, era como se eu estivesse me preparando para passar do amadorismo para o que seria mais tarde atividade regular no campo da literatura, e tendo deixado a Folha no começo de 1945, em setembro do mesmo ano me tornei crítico titular de outro grande jornal, o Diário de São Paulo, com exercício até 1947.

Ora, tendo me formado em ciências sociais na turma de 1941, eu era desde o começo de 1942 assistente de sociologia da Faculdade de Filosofia - USP, mas a literatura sempre me interessou muito mais, e o exercício da crítica mostrou que eu era capaz de trabalhar profissionalmente nela. Pensei então em passar de uma para outra na carreira universitária e por isso obtive em 1945, por concurso, o título de livre-docente de literatura brasileira, que dava automaticamente o grau de doutor em letras e me permitiu ser contratado em 1958 como professor daquela matéria na faculdade de Assis, criada então pelo governo do estado.

Mas me pareceu que antes eu estava moralmente obrigado a dar uma demonstração razoável de competência na matéria de que era assistente. Assim foi que me apliquei no preparo da tese de doutorado em sociologia, baseada na investigação de campo em áreas rurais, num tempo em que não havia a benemérita FAPESP e eu usava férias e feriados para ir até elas ou nelas residir. Entre avanços e recuos que duraram muito tempo, acabei por completar a tese, defendida e aprovada em 1954 (e publicada dez anos depois com o título de Os parceiros do Rio Bonito). Só então me considerei desobrigado para deixar a sociologia.

O concurso de 1945 acabou sendo uma revolução em minha vida, porque não só foi a causa imediata do livro Formação da literatura brasileira (que me ocupou de maneira intermitente por doze anos) mas porque o trato cada vez maior com as letras alterou a minha concepção de crítica, talvez presa um pouco demais até então à função social da literatura. Eu 
me tornara crítico de revista e jornal num momento de intensificação das leituras socialistas (com o impacto dos escritos de Marx) e de início da ação política, militando na oposição à ditadura do Estado Novo. Foi o tempo no qual, no meu caso principalmente por orientação de Paulo Emílio, tentavamos definir uma posição de socialismo independente, avesso ao stalinismo dominante, mas sem aceitar as posições trotskistas. Daí, nos meus artigos, certo viés político talvez acentuado demais. Depois do concurso procurei dosar melhor estas preocupações em relação à tônica literária, no rumo de uma crítica integrativa. Nesse processo atuaram dois abalos.

O primeiro decorreu da tese que apresentei e tratava da crítica de Sílvio Romero, autor que eu conhecia mais ou menos bem desde cedo pela leitura dos muitos livros que meu pai tinha. No curso da leitura completa e sistemática para a redação da tese, fiquei chocado com o mecanicismo da sua visão naturalista e sociológica, e senti que a minha atividade crítica até então corria risco parecido. O segundo abalo foi devido a um artigo de Cleanth Brooks Jr., "O poema como organismo”, publicado no volume que recolheu as comunicações de 1939 ao Instituto de Inglês da Universidade de Columbia, que Mário de Andrade me deu porque tinha uma duplicata. É um artigo antes modesto, mas para mim caiu na hora certa e me fez perceber que a bússola do trabalho crítico não deve ser o contexto social nem a dimensão ideológica (para os quais eu me inclinava), mas o caráter orgânico do texto, que adquire um tipo específico de autonomia. Banal, como se vê, mas para mim, naquele momento, uma revelação, que foi amadurecendo lentamente. A partir dele procurei, ao longo dos anos, ir tentando uma crítica integrativa, que deveria dar destaque ao que pode ser chamado "o próprio do texto", inclusive quando fosse preciso levar em conta fatores externos.

Tudo isso se deu nos anos de 1940, quando amoldei os meus conhecimentos pela leitura dos críticos ingleses e norte-americanos. Mas foi a partir de 1958 e da atividade docente que penso ter liquidado os restos de dogmatismo reducionista que havia nos meus artigos, ao sentir que o trabalho com os textos, não por escrito, mas nas aulas, levava a perceber como as posições teóricas muito rígidas poderiam atrapalhar a análise, porque a variedade dos textos leva a modular as abordagens. Quem precisa, como o professor, analisar textos de vária natureza lucra em adotar certa flexibilidade, praticando o que acabei por denominar "crítica de vertentes", expressão inspirada pela chuva, que corre conforme a inclinação do terreno e dos telhados. Assim, a atividade docente em literatura, que comecei aos quarenta anos, interferiu no meu trabalho, e sob este aspecto talvez os meus livros mais característicos sejam Na sala de aula e $O$ discurso e a cidade, nascidos do que se poderia qualificar como "crítica falada". Não faltará quem me censure por ecletismo sem que isso me assuste, porque, se for, pior é o torniquete dos dogmatismos. E uma coisa 
parece certa: o bom resultado do nosso trabalho depende mais das qualidades de percepção do que desta ou daquela opção teórica.

Mas a busca de certa flexibilidade não quer dizer que quem a adota fique capaz de analisar bem qualquer texto. No meu caso, talvez só quando, depois de escrever tantos anos sobre literatura passei a ensiná-la, pude amadurecer a minha concepção de crítica. O que me leva a achar que no trabalho literário é possível que o meu rendimento seja maior quando falo do que quando escrevo. Por isso disse no discurso com que agradeci em 1987 a concessão do título de doutor honorário da Universidade Estadual de Campinas:

"Sendo um homem mais de fala do que de escrita, foi como professor que me realizei melhor".

Creio que desde os tempos de Clima as circunstâncias foram me ajudando a encontrar o caminho mais adequado ao meu modo de ser e às minhas possibilidades, sem pressupor que seja o único nem o melhor, ou deva ser o dos outros. E creio que na base de tudo esteja o fato que para mim a literatura sempre teve uma posição privilegiada na tentativa de me conhecer e de conhecer tanto o meu semelhante quanto a própria vida. Tendo pouca capacidade de abstração, dependo mais da intuição e da sensibilidade, de modo que a literatura foi para mim o que são para outros a ciência e a filosofia.

Uma consequência disso foi o interesse especial pelos autores que, por assim dizer, filosofam literariamente, e ainda aqui devo registrar o papel de minha mãe que, quando eu fiz treze anos, me deu Os caracteres, de La Bruyère, numa bonita edição Garnier, cuja dedicatória na sua letra clara e decidida tenho à minha frente:

\section{"A Antonio Candido, sua mãe. \\ Poços, 24.7.931."}

Como um ovo endez, La Bruyère foi puxando Montaigne, La Rochefoucauld, Vauvenargues, os meus primeiros e fundamentais "maîtres à penser".

Falta dizer que nunca considerei a crítica um gênero cuja importância é equivalente à dos gêneros maiores, e chego a achar certa graça no tom hipercrítico de alguns de seus praticantes. E com o correr do tempo talvez a minha competência tenha encolhido em vez de aumentar, porque deixei relativamente cedo de me interessar pelas inovações teóricas. Por isso, vale a pena citar um trecho do discurso com que recebi em 2008 o Prêmio Governo de Minas Gerais, concedido então pela primeira vez:

“É sem dúvida prova de largueza de vistas por parte dos responsáveis o fato de terem contemplado um crítico de outro tempo, já de passo desacertado com as orientações recentes do seu ofício. Se me permitem uma breve nota pessoal a respeito, direi que a minha formação 
intelectual se deu nos anos de 1930 e 1940, com um prolongamento nos anos de 1950. Talvez por uma espécie de defesa, a partir de então não incorporei o que se criou no domínio dos estudos literários. Inclusive porque não sou de temperamento renovador, preferindo explorar as posições adquiridas. Admiro os que estão sempre em dia com que se propõe de novo no campo teórico, mas faço parte de outra família mental: a daqueles que, tendo conseguido elaborar um certo ponto de vista do mundo e da literatura, se fixam nelas como enquadramento suficiente".

Para terminar, assinalo que o título deste escrito é calcado no do opúsculo encantador de José de Alencar, redigido em 1878: "Como e porque sou romancista". Desculpe-se a pretensão...

Fevereiro de 2016. Antonio Candido

\footnotetext{
Antonio Candido de Mello e Souza foi escritor e ensaísta, um dos mais importantes críticos literários brasileiros. Em 1937, iniciou os cursos de Direito e de Ciências Sociais na Universidade de São Paulo. Formou-se em Ciências Sociais em 1941. Tornou-se livre-docente de Literatura Brasileira em 1945 e doutor em Ciências em 1954. Em 1974, passou a professor titular de Teoria Literária e Literatura Comparada da USP, cargo em que se aposentou em 1978. Foi professor associado de Literatura Brasileira na Universidade de Paris, de 1964 a 66, e, em 1968, professor visitante de Literatura Brasileira e Literatura Comparada na Universidade de Yale. Foi coordenador do Instituto de Estudos da Linguagem (IEL) da Unicamp, de 1976 a 78 . Foi professor-emérito da USP e da UNESP, doutor honoris causa da Unicamp e professor honorário do IEA. De suas obras de crítica literária, a mais importante é Formação da Literatura Brasileira (Momentos Decisivos), de 1959. Como ensaio sociológico, é considerado clássico seu estudo sobre o caipira paulista e sua transformação, Os Parceiros do Rio Bonito (1964). Entre os prêmios recebidos estão: Jabuti de Literatura (1965 e 1993); Machado de Assis (1993); Anísio Teixeira (1996); Camões (1998) e Juca Pato (2007). Faleceu em 12 de maio de 2017.
} 